\title{
European approaches to sustainable work: introductory remarks
}

\author{
Kenneth Abrahamsson \\ Maria Albin \\ Elisabeth Lagerlöf \\ Chris Mathieu
}

Globalisation, digitalisation, international competition, new demographic and technological transformations have fundamental impacts on working conditions, working hours and the location of work. The development towards work without boundaries, a platform economy and labour market polarisation have significant repercussions for employment relations, social protection, and the role of social partners. Temporary jobs and precarious working conditions are increasing in the service sector, while high-performance jobs become more common in the advanced manufacturing sector. More knowledge is needed on how to accomplish secure and adaptable employment, health and safety at work, proper work life balance, a good social dialogue and effective participation of workers. New workplace innovations for job quality, productivity and growth become increasingly necessary on the road to future work. Equality, social protection, and improvement of living conditions are major visions both in the ILO's 2019 centenary mission, and in the UN Sustainable Development Goals to be attained by 2030.

The theme for this double issue of European Journal of Workplace Innovation is to highlight European approaches to sustainable work, digitalisation and job-related transitions looking at next policy steps in the implementation of the European Pillar of Social Rights. A starting point for this research initiative was a Swedish project, headed by Maria Albin, of the Karolinska Institute, and financed by the Swedish Innovation Agency, Vinnova, to strengthen research on sustainable work in the European Framework Programme Horizon 2020, and later Horizon Europe.

During this project journey initiated in 2013, we have broadened the connotation of sustainable work, to reflect on European workplaces as such and their capacity to meet future challenges. In 2019 the policy discussion and research on the future of work was extremely intense. The ILO, OECD, the EU Commission as well as many policy producing institutions were actively involved in framing futures of work in times of digitalisation, climate change and just transition.

In 2020, many future ideas have collapsed as an effect of the Covid-19 pandemic with its fundamental and its far-reaching Europe-wide shock impacting the economy, labour market 
and working life, public and occupational health, family and living conditions, following on various organisational, social and mental lockdowns. The policy process has not, however, been caught in a revolving door, with sustainable work out and Covid-19 in. On the contrary, the need for an in-depth discussion of sustainable work in Europe and the global context, is even stronger in this new situation.

Much of the content found in this double issue was initially presented at a multidisciplinary conference in October 2018 convened by the Vinnova-financed platform on Sustainable Work in EU Horizon 2020, and held at the Ingvar Kamprad Design Centre, Lund University. The purpose of the conference was twofold. Firstly, it comprised reports of the platform project as such, and relevant policy initiatives and meetings that had been organized from 2013 to 2018. A second aim was to provide an overview of ongoing activities in Nordic countries, the EU and ILO, concerning development towards a sustainable working life, in order to make an impact on the next European Framework Research Programme, Horizon Europe, as well as the then still existing Horizon 2020. A total of around one hundred people participated in the conference, representing all the Nordic Work Environment Institutes, the PEROSH Network for European Institutes, EU OSHA and Eurofound, as well as several leading researchers in various areas (www.sustainablework2020.se).

One of the key-speakers was Allan Larsson, former adviser to Jean-Claude Juncker on the European Pillar of Social Rights and involved in the ILO work on Future of Work. His presentation highlighted the development of various welfare and labour market models and economic development from WW2 to current times. One of the challenges discussed at the conference was how individuals and employees can claim their rights in the new gig or platform economy. How do you negotiate with a platform or algorithm? How can we change direction to meet the widespread social and political discontent, strengthen the social contract, and start a new social recovery?

Another field of interest covered at the conference was job longevity, health and labour law regulation, challenges at work in times of digitisation, new perspectives on ergonomics and exposure research. Attention was also paid to the social dialogue, the quality of work and sustainable workplaces. The Nordic countries have a strong tradition in occupational health and safety research, as well as in research on sustainable work systems. The strategic importance of sustainable work, as a resource for health, innovation, and growth, is emphasised in the European innovation strategy, and by the social partners. Therefore, workplace innovation and workers' health and wellbeing need to be a more visible and coherent theme in the EU's research programme Horizon Europe.

Sustainable work and sustainable work systems have been used as a policy concept and buzzword in working life and research during the last two decades. Sustainable work aims at illuminating and supporting a process to cope with present and future challenges at the workplace: it is not a product nor an end goal. A sustainable workplace reflects the reconciliation between health, the development of work environment for the employees, and a productive and value-creating mission for the enterprise or production organisation. 
The purpose of this two-volume issue is to place sustainable work in context. The first issue focuses on the future of work and the transformation of the European workplace from a policy perspective, while the second issue shares reflections, models, and results from various research positions. The first contribution by Allan Larsson, former Director General of DG Employment and adviser to Jean-Claude Juncker, and Kenneth Abrahamsson, adjunct professor, Luleå University of Technology, has a challenge-oriented perspective looking at the innovation-driven digital transformation, and the policy-driven climate transition in the context of pandemic-driven restructuring of important sectors of our economies and societies. The next article by Kenneth Abrahamsson illuminates and describes various understandings and aspects of the concept of sustainable work. The shifting character of the European workplace will also have repercussions for the concept of sustainable work as such, and its relation to workplace innovations, job quality, precarious work, and climate change. Sustainable work is also a response to climate change and the greening of European enterprises, production systems and workplaces.

Which policy priorities, programme initiatives and calls are needed to highlight sustainable work as a core issue in Horizon Europe? Through reflecting on the Swedish Platform for Sustainable Work in Horizon 2020, Maria Albin, Professor of occupational- and environmental medicine at the Karolinska institute, and Elisabeth Lagerlöf, senior consultant, describe formal and non-formal ways to strengthen sustainable work as a central theme in European research. This is a joint challenge for policy, the research community, as well as European agencies and networks such as EU-OSHA, Eurofound and PEROSH.

The first issuee also comprises three contributions from European actors. Franz Eiffe, PhD and research officer at Eurofound, gives an overview of Eurofound's Reference Framework and the Context of Sustainable work. His article focuses on sustainable work in a life-course perspective. William Cockburn, head of the prevention and research unit at EU OSHA, the European Agency for Safety and Health at Work, presents an institutional perspective and highlights policies, priorities, and ways of work on OSH in the future. The work of the European network for national work environment institutes, PEROSH is presented by Mary Paulien Bongers, chairperson, Mary Trainor, chair of the scientific steering group, and Jan Michiel Meeuwsen, PEROSH's Manager of International Affairs. Finally, Lennart Levi, Professor Emeritus in psychosocial medicine, Karolinska Institute, and one of the pioneers in Swedish occupational health research, presents a global survival perspective on Stressors at Work and Elsewhere by focussing the challenges of Agenda 2030 for the world of work.

The second issue comprises challenge-driven research for a sustainable working life. Job longevity is a core aspect of sustainable work in a life-course perspective. By looking at institutional contexts and figures, Bjørn Einar Halvorsen, former director general, and senior adviser, from Norway discusses and analyses the high and rising rate of senior employment in the Nordic countries. Job longevity and the mobilisation of the workforce into the third age can also be seen from an equality and gender perspective. As been shown by Maria Albin, professor, and Theo Bodin, associate professor, Institute of environmental medicine, 
Karolinska Institute and Eskil Wadensjö, Professor in labour economics, Institute for social research, University of Stockholm, the social gradients in health and working conditions in combination with gaps in the supportive welfare systems result in job longevity being in part a problematic and unequal process.

Two articles touch issues of innovations, new technology, and quality of work. The first article, on the relationship between job quality, innovation, and employment, authored by Chris Mathieu, Principal Investigator, and Susanne Boethius, Project Manager of the Horizon 2020 project QuInnE - Quality of Jobs and Innovation Generated Employment Outcomes (both at Department of Sociology, Lund University) presents the major findings of that project on the reciprocal relations between job quality and innovation. The pros and cons of sustainable work, digitisation and new production systems is the focus of the contribution from Lena Abrahamsson, Chair Professor in human work science, and Jan Johansson, Professor in industrial work environment, both at Luleå University of Technology.

Finally, two texts relate to the importance of the social dialogue on the national, Nordic, and European levels. Firstly, stakeholder collaboration, inspired by the Nordic model for sustainable work and competitiveness during an industrial startup, is studied in a new highgrowth entrepreneurial firm by Ulrika Harlin, LicEng MSc, and Katrin Skagert, PhD, both researchers at RISE, Research Institutes of Sweden, Martina Berglund, PhD, Assistant professor at the Department of Management and Engineering at Linköping University, and Mattias Elg, Professor of Quality Technology and Management, centre director at HELIX Competence Centre at Linköping University. Secondly, Anders Kjellberg, Professor of Sociology, Lund University, looks at the shifting role of trade unions in the social dialogue by using models, institutional settings, and statistics to track developments both in a Swedish and European perspective. So, what is the next step for research on sustainable work in Europe? In some concluding remarks, the editorial group reflects on policies, institutional factors and research needed in the effort to foresee and form the Future of Work in Europe in the context of Agenda 2030 and the new research challenges and missions articulated in Horizon Europe.

\section{About the authors}

Kenneth Abrahamsson, Adjunct Professor in human work science, Luleå University of technology and Associate Professor, Department of Education, University of Stockholm. He is now a senior consultant and is a member of the Swedish platform for sustainable work in Horizon 2020 and Horizon Europe.

Maria Albin, M.D. Professor of occupational health, Institute of Environmental Medicine, Karolinska Institute, former MD and Docent in occupational and environmental medicine at the Medical faculty in Lund. Before that she was the project leader of the "Metalund", a research and competence centre to increase knowledge and understanding of different 
environmental factors' influence on health. She is also the initiator of the Swedish platform for sustainable work in Horizon 2020 and Horizon Europe.

Elisabeth Lagerlöf, M.A. Senior Consultant since 2008. Has worked as Head of Information, Eurofound, Ireland 2001-2007; Director, NIVA Education, Finland 1998 - 2001; Project manager, EU-OSHA, Spain 1996 -1998, and Work Environment Attaché, Swedish Embassy, Washington DC, USA 1984 -1987; In Sweden as researcher 1968-1984 and as Director Information and International Affairs, Swedish Institute of Working Life 1987 - 1996.

Chris Mathieu, Department of Sociology, Lund University was PI and project coordinator on the Horizon 2020 project QulnnE. He currently works in the Horizon 2020 projects Beyond 4.0 and DiHECO. Mathieu is currently co-editing The Oxford Handbook of Job Quality (OUP). 